\title{
High resolution seismic velocity structure around the Yamasaki fault zone of southwest Japan as revealed from travel-time tomography
}

\author{
Andri Dian Nugraha ${ }^{1}$, Shiro Ohmi ${ }^{2}$, Jim Mori $^{2}$, and Takuo Shibutani ${ }^{2}$ \\ ${ }^{1}$ Global Geophysics Research Group, Faculty of Mining and Petroleum Engineering, Institute of Technology Bandung, 40132, Indonesia \\ ${ }^{2}$ Disaster Prevention Research Institute, Kyoto University, Gokasho, Uji 611-0011, Japan
}

(Received August 4, 2012; Revised December 1, 2012; Accepted December 13, 2012; Online published September 17, 2013)

\begin{abstract}
The Yamasaki fault zone in southwestern Japan currently has a high potential for producing a large damaging earthquake. We carried out a seismic tomographic study to determine detailed crustal structures for the region. The velocity model clearly images a low-velocity and high $V_{p} / V_{s}$ (high Poisson's ratio) anomaly in the lower crust beneath the Yamasaki fault zone at a depth of $\sim 15-20 \mathrm{~km}$. This anomaly may be associated with the existence of partially-melted minerals. The existence of this anomaly below the fault zone may contribute to changing the long-term stress concentration in the seismogenic zone.
\end{abstract}

Key words: Yamasaki fault, travel-time tomography, velocity structure.

\section{Introduction}

The Yamasaki fault zone is one of the seismically most active onshore faults in southwestern Japan. This tectonic feature is a left-lateral active fault zone with a length of approximately $80 \mathrm{~km}$ running northwest to southeast from Okayama to Hyogo Prefectures. Damaging earthquakes have not occurred for about 1100 years, and the largest recent event was a $M 5.6$ event on May 3, 1984, near the Kuresaka-Toge fault.

The level of small earthquakes is relatively high in the Yamasaki fault zone, with about $3000 M 0.0$ to $M 3.0$ occurrences per year. Previous studies show that the seismic activity of the region appears to have a periodicity of 5-6 years, and, since 2001, activity appears to have migrated toward the southeast along the fault zone (Nakao et al., 2004) around the Kuresaka-Toge, Yasutomi, and Biwako faults. Watanabe et al. (1996) investigated the crustal movement around the Yamasaki fault zone after the $1995 M_{\mathrm{w}} 6.9$ Kobe (Hyogo-ken Nanbu) earthquake, located about $50 \mathrm{~km}$ to the southeast. They showed that the seismicity of the Yamasaki fault zone became active after the occurrence of this earthquake, while the areas outside the fault zone did not show any significant increase, suggesting that an active fault is sensitive to the crustal stress concentration. The Yamasaki fault zone is an onshore active fault that has the potential to generate a large earthquake and cause severe damage. Therefore, the study of the physical properties of this fault for the purposes of earthquake hazard mitigation is very important.

Previous tomographic studies in other regions of Japan have showed varied results concerning the relationship between earthquake source regions and the seismic velocity

Copyright (c) The Society of Geomagnetism and Earth, Planetary and Space Sciences (SGEPSS); The Seismological Society of Japan; The Volcanological Society of Japan; The Geodetic Society of Japan; The Japanese Society for Planetary Sciences; TERRAPUB.

doi:10.5047/eps.2012.12.004 structure. For example, Zhao et al. (1996) reported a low seismic velocity and a high Poisson's ratio anomaly around the hypocenter of the 1995 Kobe earthquake. They showed that this anomaly may be due to high pore fluid pressure and a fluid-filled, fractured rock matrix near the bottom of the seismogenic layer that contributed to the initiation of the Kobe earthquake. Shibutani et al. (2005) showed the relationship between the source process of the 2000 western Tottori earthquake and the three-dimensional velocity structure. They found that the slip is small for the high-velocity regions and large in the shallow low-velocity regions, and concluded that crustal structure heterogeneity could control the rupture process of the mainshock. A tomographic study of the 2004 mid-Niigata prefecture earthquake by Okada $e t$ al. (2005) concluded that the high-velocity area with low $V_{p} / V_{s}$ values, imaged in the footwall, was considered to be old basement rock, while, the low-velocity areas with high $V_{p} / V_{s}$ values in the hanging wall were associated with sediments. Nakajima et al. (2006) investigated the major features of the complex seismic velocity structure around the Nagamachi-Rifu fault in northeastern Japan, with implications for the existence of fluid-rich regions in the mid to lower crust as indicated by low velocity and high Poisson's ratio anomalies.

Previous regional tomographic studies in southwestern Japan include Nakajima and Hasegawa (2007), which focused on the deep magma source beneath the Chugoku district and the deep structure beneath the Kii Peninsula. Another study by Matsubara et al. (2008) constructed seismic velocity structures for the entire Japan Islands with a unified resolution. However, these studies do not focus on the crustal structure around the Yamasaki fault zone. In this study, we report the results of high-resolution travel-time tomography using a large data set obtained by a dense seismic network. The analyses of this large data set enables resolution of the details of the regional velocity structure that have not been previously recognized; in particular, low- 
(a)

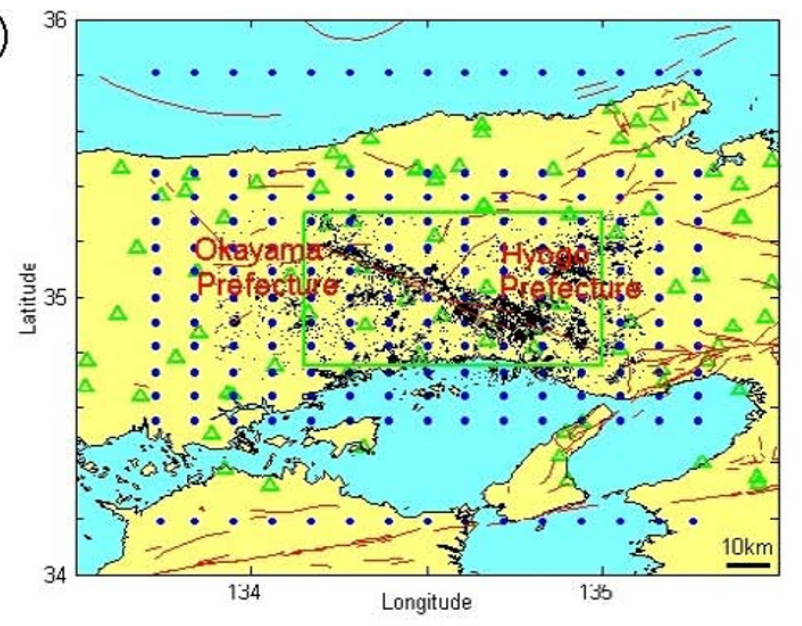

(b)
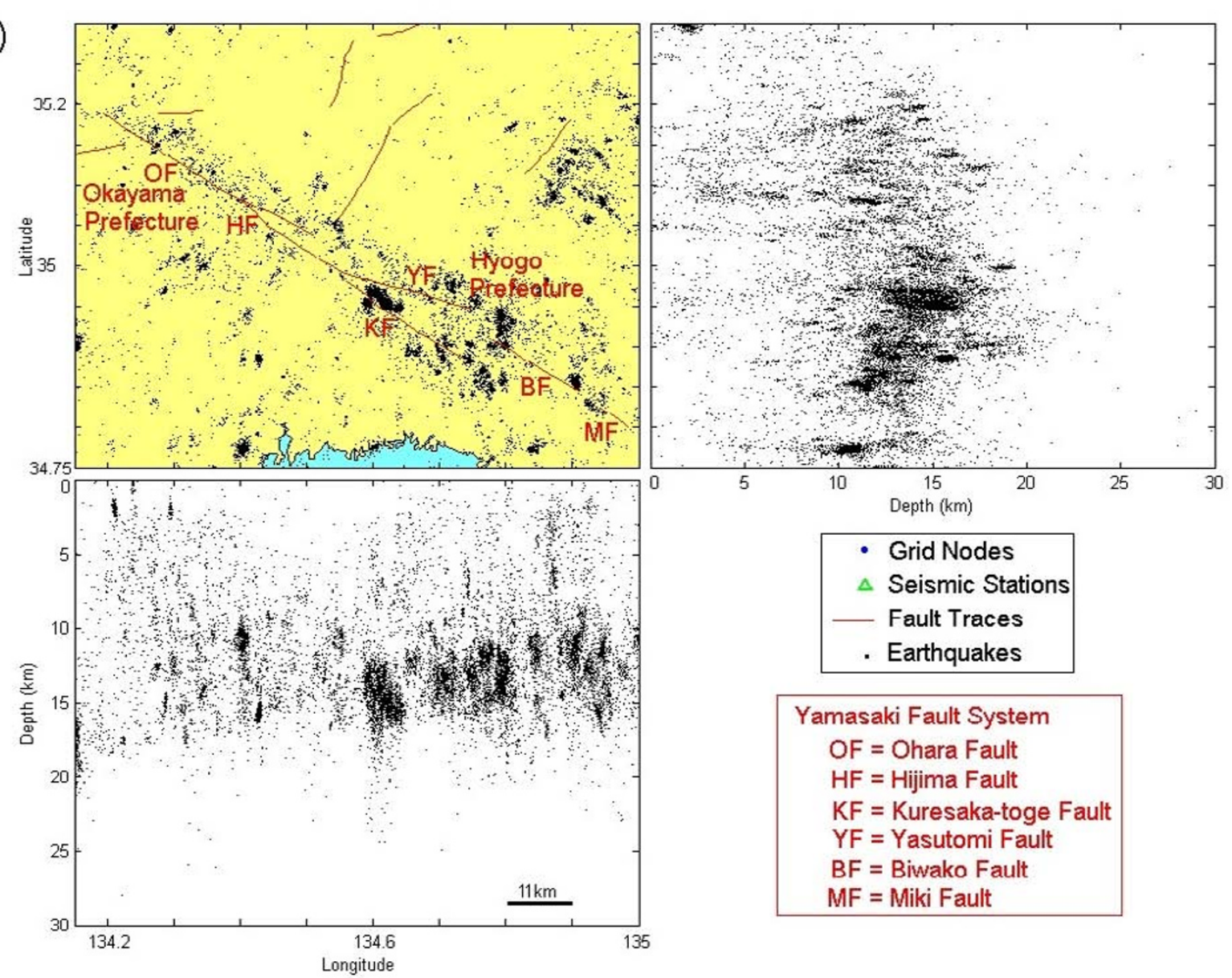

Depth $(\mathrm{km})$

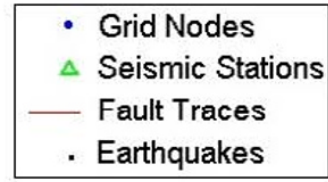

\begin{tabular}{|l} 
Yamasaki Fault System \\
OF $=$ Ohara Fault \\
HF $=$ Hijima Fault \\
KF $=$ Kuresaka-toge Fault \\
YF $=$ Yasutomi Fault \\
BF $=$ Biwako Fault \\
MF $=$ Miki Fault
\end{tabular}

Fig. 1. Map of study area (a) and distribution of relocated hypocenters (black dots) along with cross-sectional views of 16,797 events that were used for the inversion in this study (b). The fault traces (red lines) and abbreviated names of segments of the Yamasaki fault system are also shown. OF is Ohara Fault, HF is Hijima Fault, KF is Kuresaka-Toge Fault, YF is Yasutomi Fault, BF is Biwako Fault, and MF is Miki Fault. The green rectangle indicates the area of Fig. 2.

velocity zones and regions of high $V_{p} / V_{s}$. The purpose of the study is to examine detailed crustal structures in, and around, the Yamasaki fault and its relation to the process of large earthquake generation.

\section{Data and Methods}

In this study, we used local $P$ and $S$ phase data to determine the three-dimensional $P$ and $S$ wave velocity $\left(V_{p}\right.$, $\left.V_{s}\right), V_{p} / V_{s}$ ratio, and Poisson's ratio $(P R)$ structures in and around the Yamasaki fault zone of southwestern Japan. The data from June 1976 to December 2007 were collected by the Abuyama and Tottori Observatories, Disaster Prevention Research Institute (DPRI), Kyoto University, the University of Tokyo, National Research Institute for Earth Science and Disaster Prevention (NIED), National Institute of Advanced Industrial Science and Technology (AIST), and the Japan Meteorological Agency (JMA). The initial precise hypocenters (including arrival times) for the 

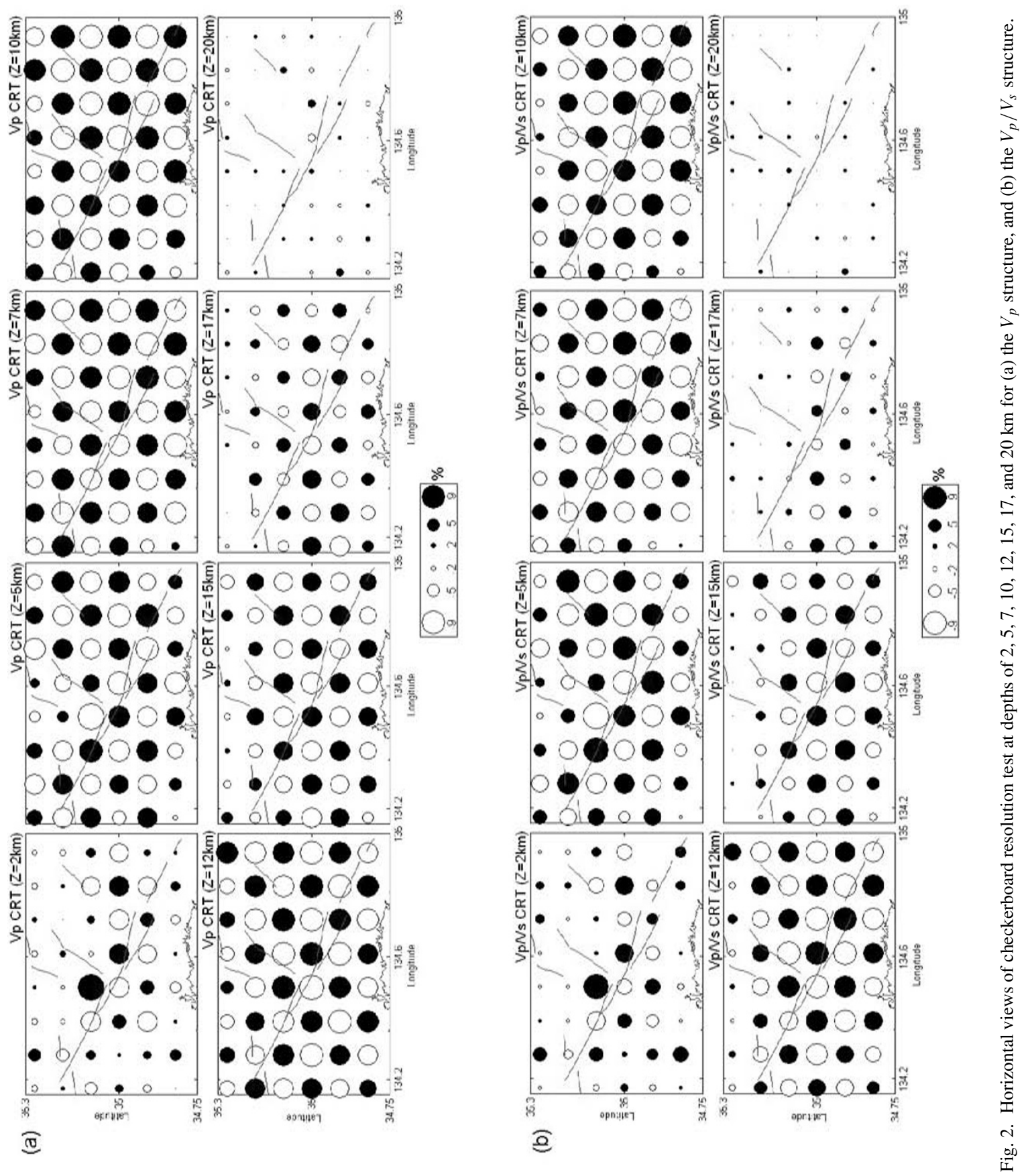
tomographic inversion in this study were obtained from the Shibutani et al. (2008) result using a Joint Hypocenter Determination (JHD) method (Kissling et al., 1994) with, simultaneously, inversion for a 1-D velocity structure. We selected 16,797 small ( $M 0.1-M 0.6)$ local earthquakes around the Yamasaki fault zone that generated 174,271 $P$ and 154,406 $S$ wave arrival times, as shown in Fig. 1(a) and 1(b). $P$ and $S$ arrival times have assigned picking uncertainties of typically $0.01-0.1 \mathrm{~s}$, with larger uncertainties on the $S$ wave. Events were chosen that had arrival times at 10 stations, or more, and covered the geographical area as well as possible.

We used the SIMULPS12 method (Eberhart-Phillips, 1993; Evans et al., 1994) which provides a local earthquake algorithm inversion to calculate simultaneously the 3-D $V_{p}$ and $V_{p} / V_{s}$ structure and hypocentral adjustments. Predicted arrival times through the 3-D structure are calculated for ray paths using the pseudo-bending technique of Um and Thurber (1987). Since the $S$ data are fewer in number and, generally, of lesser quality than the $P$ data, the calculation of $V_{p} / V_{s}$ using $S$ - $P$ times rather than from separate estimates of $V_{s}$ and $V_{p}$ is usually more robust (EberhartPhillips, 1993). We used grid nodes spaced at $10 \mathrm{~km}$ in the horizontal direction and $2-3 \mathrm{~km}$ in the vertical direction for the tomography inversion, as shown in Fig. 1(a). The initial $V_{p}$ and $V_{p} / V_{s}$ models for the tomographic model are from Shibutani et al. (2008).

\section{Model Resolution}

The resolution of the tomographic model is evaluated using a checkerboard resolution test (CRT), in which a regular pattern of fast and slow velocities is examined using the inversion procedure. The CRT pattern was set with alternating fast and slow velocities at each grid point with a contrast of $\pm 10 \%$. A synthetic set of travel times is created for the checkerboard velocity using the same ray paths present in the real data, and then the synthetic times are inverted to see how well the starting model is recovered. The CRT results for both $V_{p}$ and $V_{p} / V_{s}$ models show good resolution beneath the Yamasaki fault regions at depths of 2-17 km (Fig. 2). The good CRT recovery results are supported by high hit-counts (RHC) of over ten thousand rays that crisscross the region (Fig. 3). However, the CRT is poorly recovered at depths greater than $17 \mathrm{~km}$ beneath this region due to lack of ray paths. In this test, random noise was not added to the travel times so this result mainly shows the relative resolution for various regions of the model.

We also applied other techniques to estimate the model resolution in the 3-D tomography. We calculated the diagonal resolution element matrix $R$ for the damped leastsquares problem (Menke, 1989) and the derivative weight sum (DWS) (Toomey and Foulger, 1989). For the diagonal element matrix, values of 1.0 indicate that the model parameters are completely resolved and values of 0.0 indicate that the model parameters are completely unresolved. The DWS is a useful measure of the ray density in the neighborhood of the nodes and is similar to the ray hit-count, but weighted by the ray-node separation and ray path length in the vicinity of the node. The diagonal resolution elements show high values of $0.5-0.9$ (Fig. 4 ) that coincide with high values of the DWS (Fig. 4) which are over 10,000 beneath the Yamasaki fault system. The model resolution test results including CRT, the diagonal element matrix, and DWS, indicate good resolution at depths of $2-17 \mathrm{~km}$ beneath the Yamasaki fault system. Therefore, we consider that the velocity models in this study were adequately resolved by the tomographic inversion.

\section{Seismic Tomographic Images}

We show the results for the $V_{p}$ and $V_{s}$ structures in Figs. 6, 7, and 8 , which plot the percentage perturbation from the initial 1-D model. Also shown are values for the $V_{p} / V_{s}$ and $P R$ structures. Figure 6 shows cross-sections along, and through, the Yamasaki fault zone and Fig. 7 shows map views at various depths from $2-20 \mathrm{~km}$.

The tomographic inversion results show a highly heterogeneous crustal structure around the Yamasaki fault zone. We identify four prominent areas of low velocity in the region. The four features all have different seismic properties, as summarized in Table 1.

In the shallower part of the crustal structure from the surface to $5-\mathrm{km}$ depth below the Hijima fault, there is a region of low $V_{p}$ and low $V_{s}$ that coincides with low $V_{p} / V_{s}$ and low $P R$ (Anomaly 1). This is seen in the Line-3 crosssection of Fig. 6. There is a similar region of low velocity at a shallow depth beneath the Kuresaka-Toge fault; however, the $V_{p} / V_{s}$ is moderately high (Anomaly 2), as seen in Line6.

In general, we observe high $V_{p} / V_{s}$ ratios and high $P R$ in the regions beneath the Yamasaki fault zone (Fig. 6) at depths of $\sim 15-17 \mathrm{~km}$. At depths of $15-20 \mathrm{~km}$ beneath the Hijima fault, there are prominent low velocities (low $V_{p}$ and low $V_{s}$ ), high $V_{p} / V_{s}$, and high $P R$. These can be clearly seen in Line-4 of the cross-sections in Fig. 6 (Anomaly 3). At depths of 15-20 km beneath the Kuresaka-Toge fault, there is a region of moderately high $V_{p}$, low $V_{s}$ anomaly, with high $V_{p} / V_{s}$ and high $P R$ (Anomaly 4). This can be seen in Line 6 of Fig. 6.

We evaluated the resolution of the tomographic model using three different methods, including a checkerboard test, the diagonal of the resolution element matrix, and the derivative weight sum (DWS) (Toomey and Foulger, 1989). Overall, there is relatively good resolution of both the $V_{p}$ and $V_{p} / V_{s}$ models for depths of 2-17 km. The checkerboard test (Fig. 6) shows good recovery, the diagonal of the resolution elements have high values ranging from 0.4 to 0.9 (Fig. 5), the DWS has high values of over 10,000 (Fig. 4), and these are supported by high ray hit-counts of over 10,000 (Fig. 3).

\section{Interpretations}

Seismic velocities and Poisson's ratios vary in crustal rocks depending on factors such as pressure, temperature, composition, crack density, and fluid content. A laboratory study by Takei (2002) showed that the effect of fluids on seismic velocity depends on the type of fluids, such as meltfilled pores, or water-filled pores, as well as the shape of the fluid-filled pores. The existence of melt-filled pores decreases seismic velocity and increases $P R$. The meltfilled pores are independent of the shape of the pores. On 

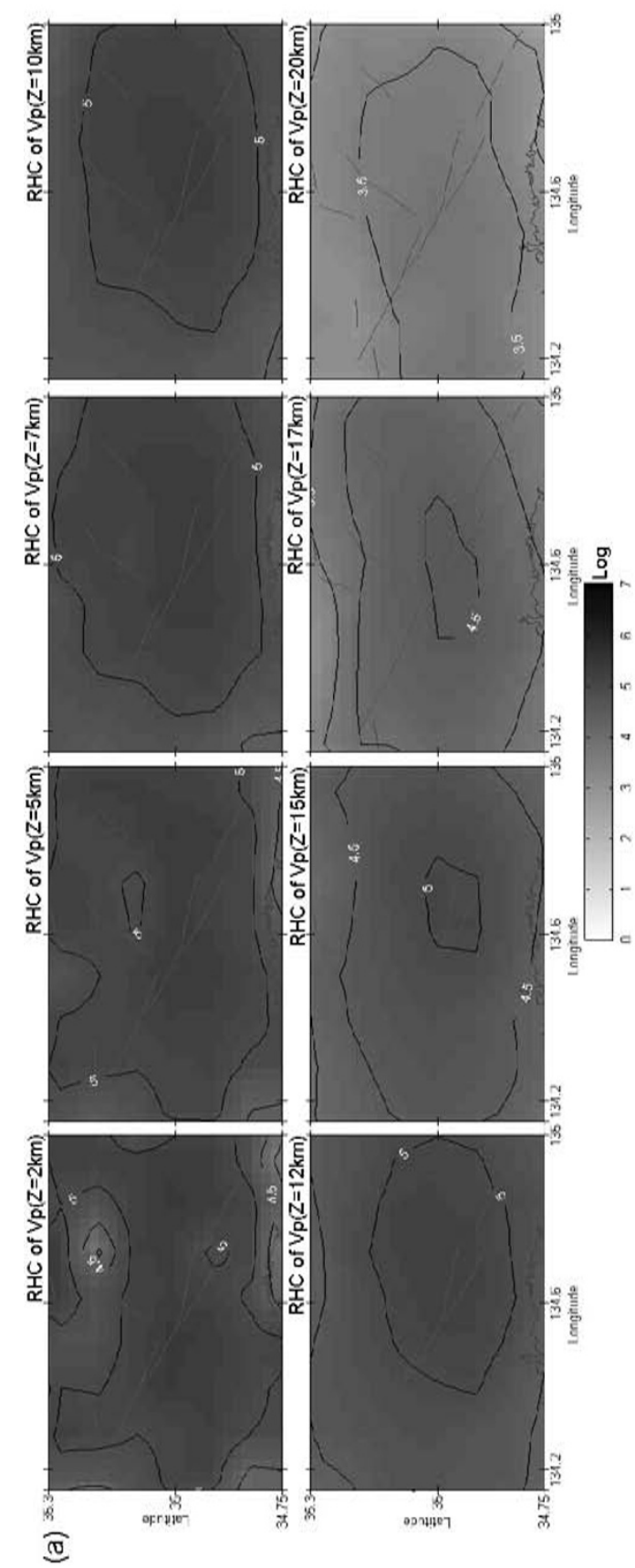
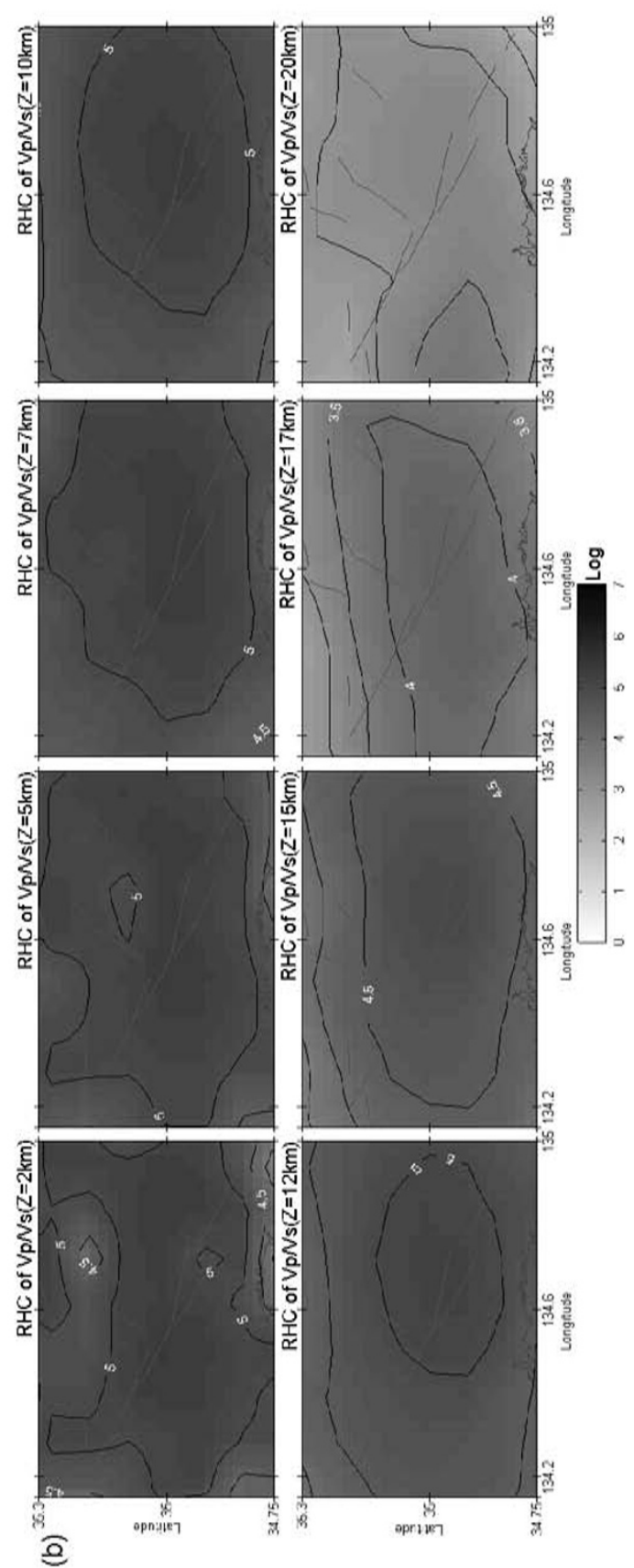

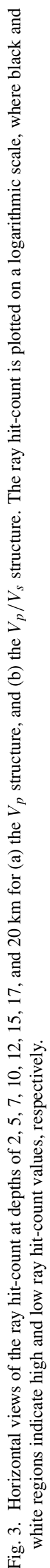



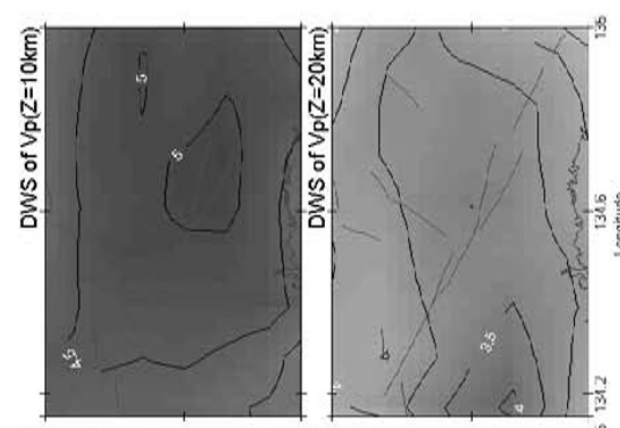

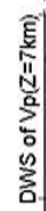
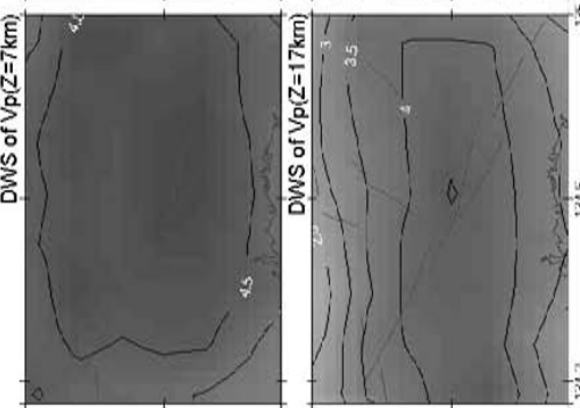

ह⿱宀

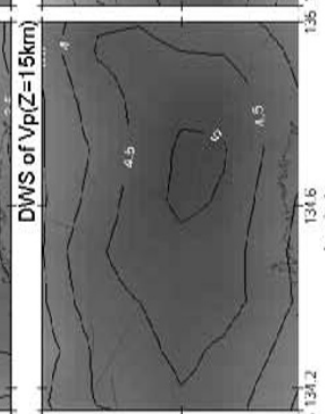

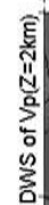

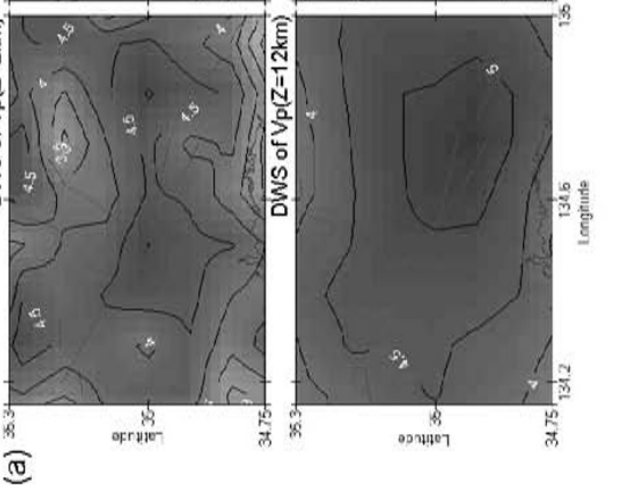

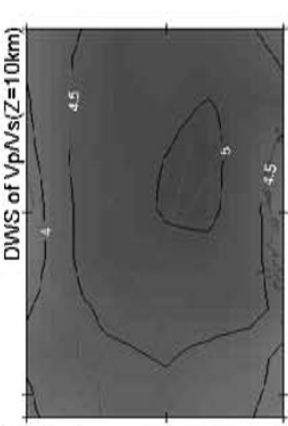
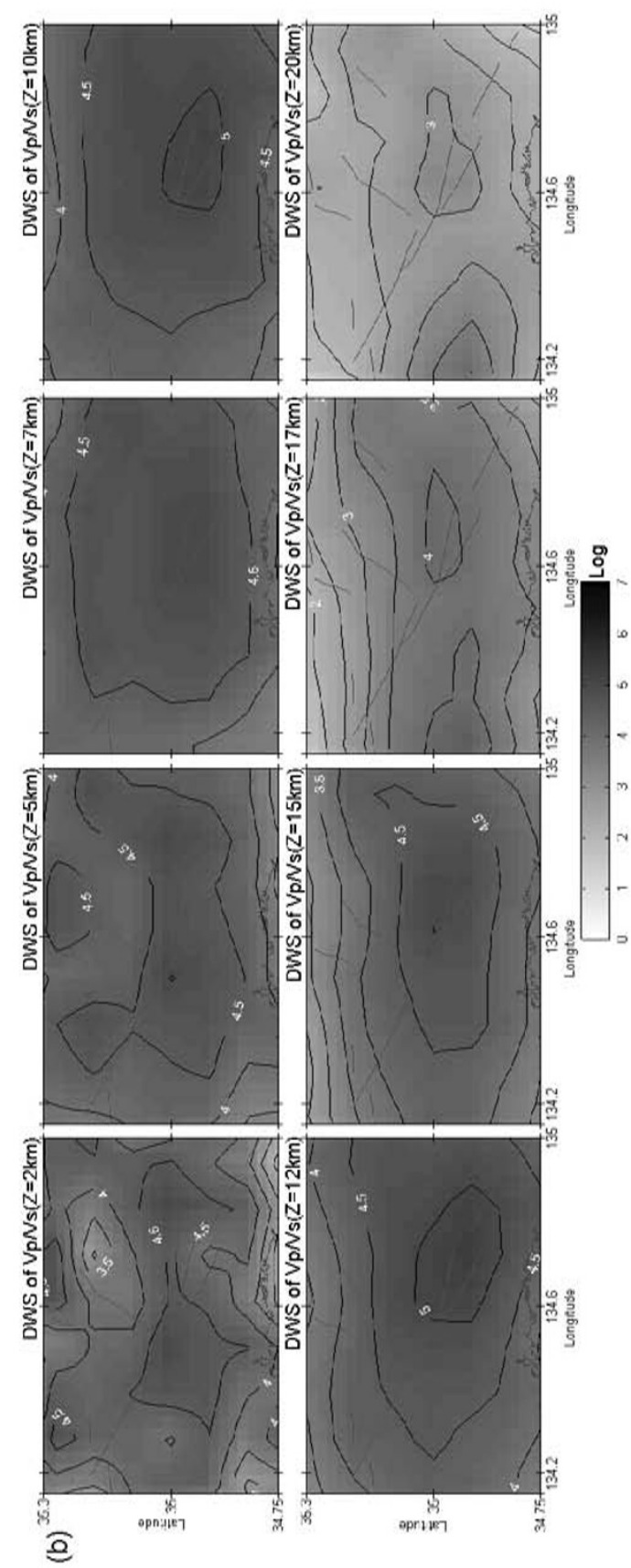

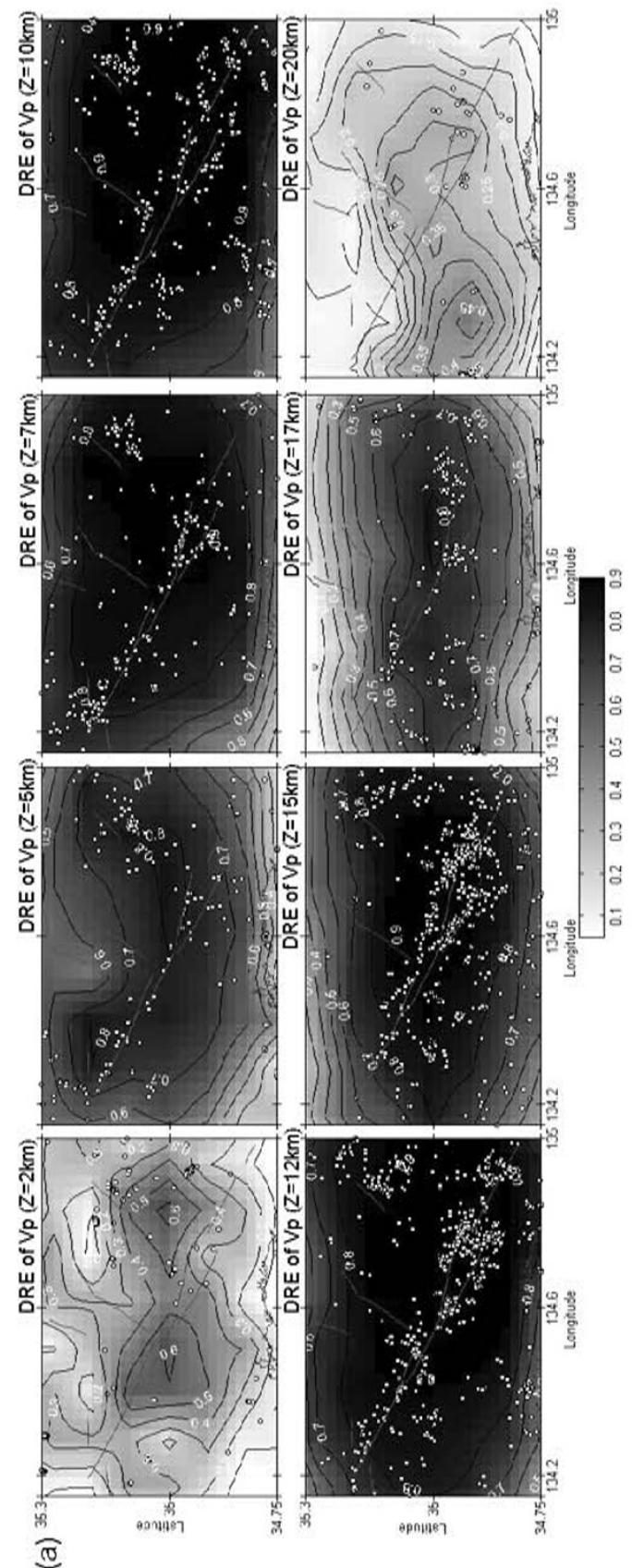
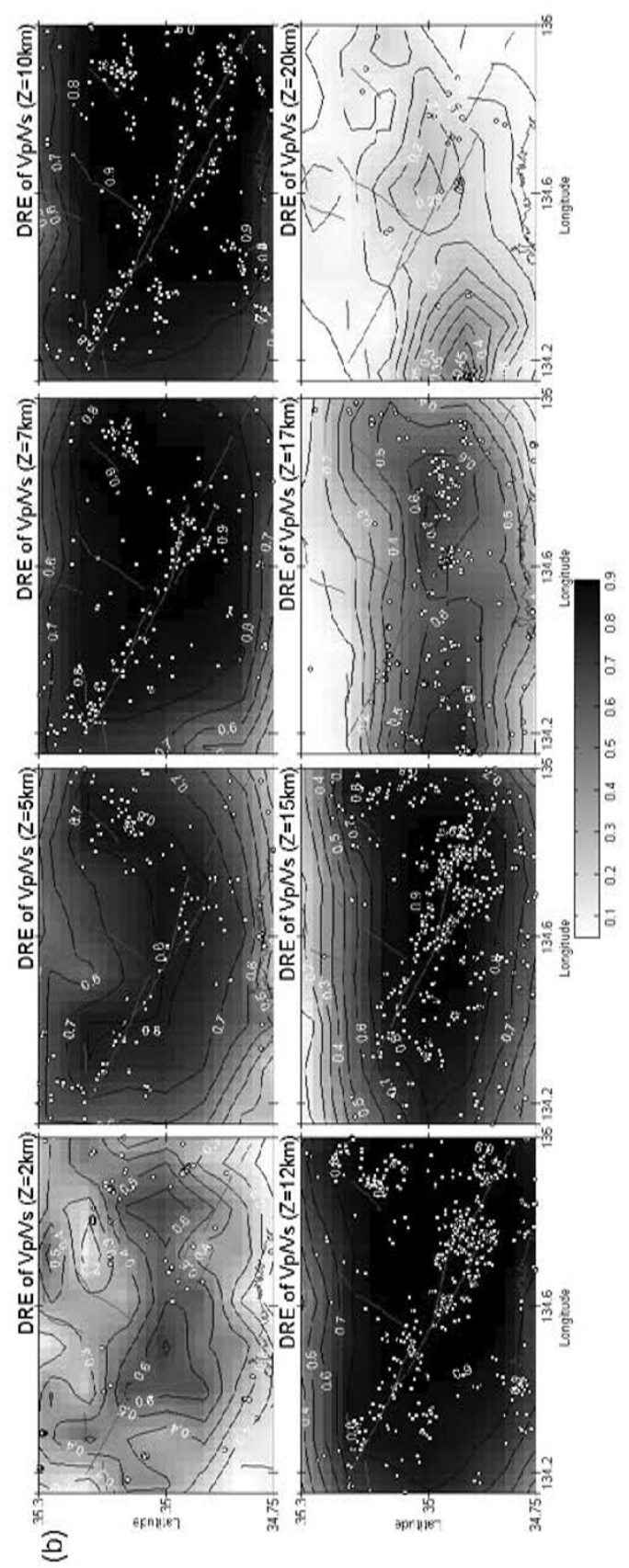

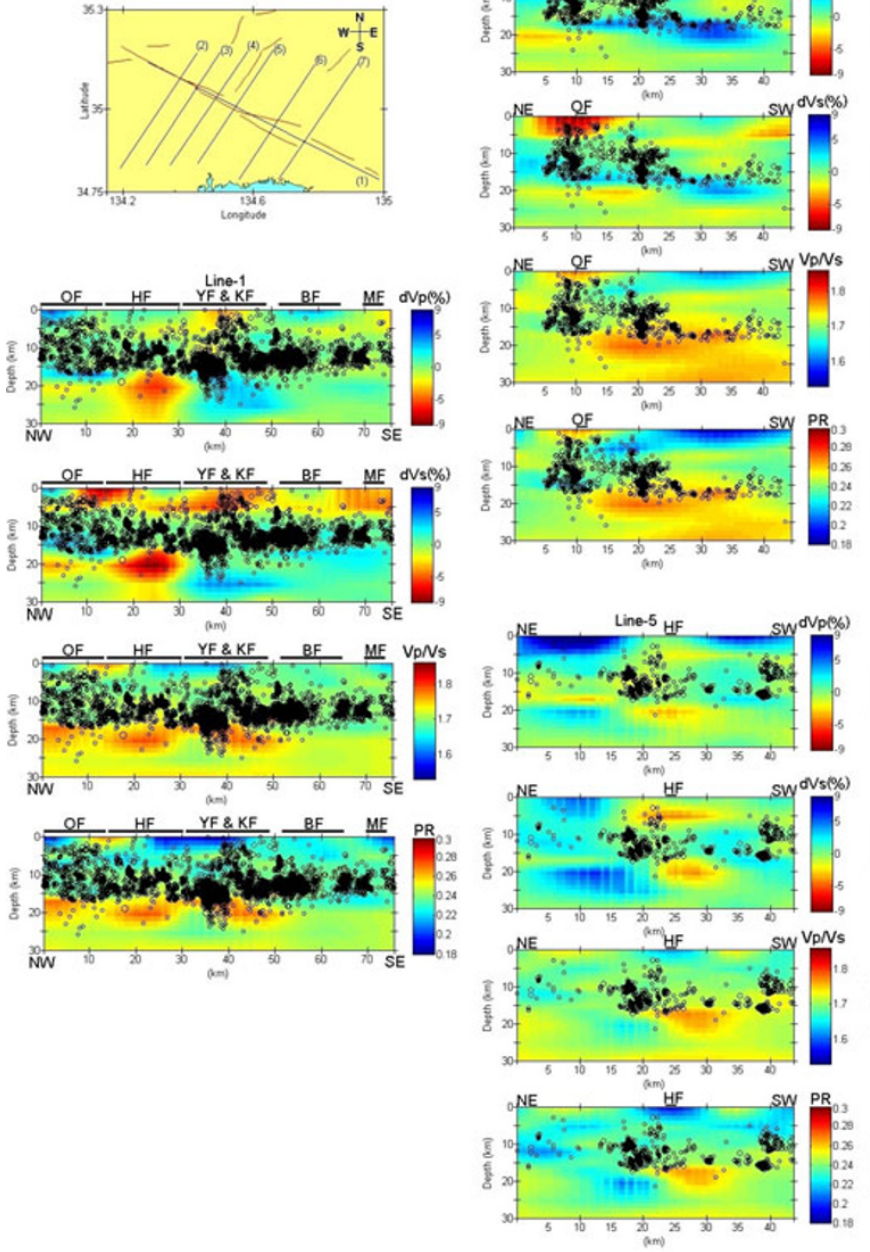
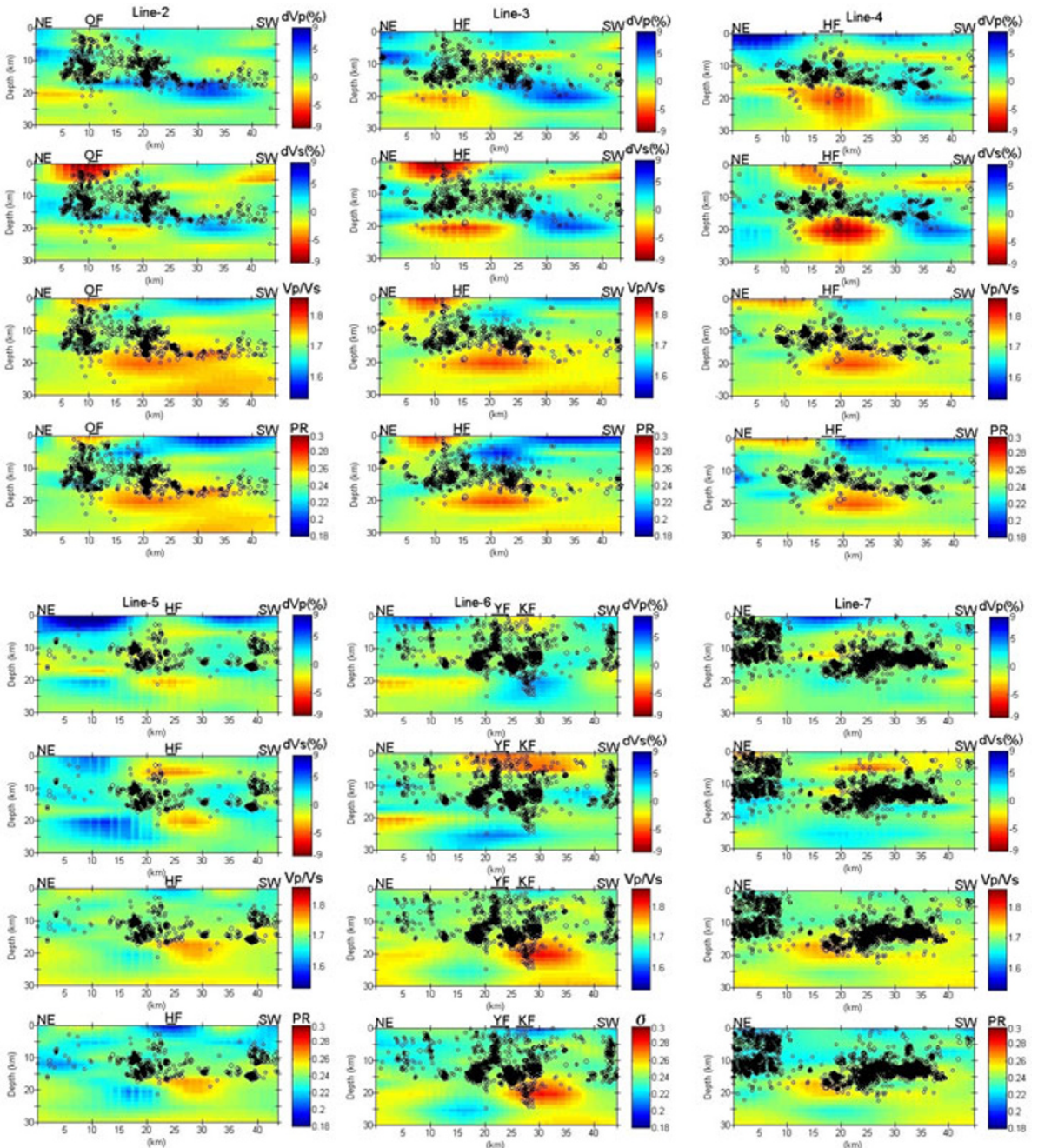

Fig. 6. Cross-sections of the $V_{p}$ and $V_{s}$ perturbation, $V_{p} / V_{s}$ ratio, and Poisson's ratio (PR) along the Yamasaki fault zone (Line-1), through the Ohara fault (Line-2), through the Hijima fault (Line-3, Line-4, and Line-5), through the Yasutomi and the Kuresaka-Toge faults (Line-6), and through between the Kuresaka-Toge and the Biwako fault (Line-7). Black circles indicate relocated hypocenters in the vicinity of a line ( $2 \mathrm{~km})$. The cross-sections have a vertical exaggeration of 1.8 .

Table 1. Summary of the features of four anomalies beneath the Yamasaki fault.

\begin{tabular}{lcccc}
\hline & Anomaly 1 & Anomaly 2 & Anomaly 3 & Anomaly 4 \\
\hline$V_{p}$ & Low & Low & Low & Moderate to high \\
$V_{s}$ & Low & Low & Low & Low \\
$V_{p} / V_{s}$ & Low & Moderate to high & High & High \\
$P R$ & Low & Moderate to high & High & High \\
\hline
\end{tabular}

the other hand, water-filled pores have a different effect on seismic velocity and $P R$, which depends on the shape of the pores (Takei, 2002). Water-filled pores of a small aspect ratio decrease seismic velocity with increasing $P R$, which is the same effect as for melt-filled pores. Water-filled pores of a large aspect ratio, however, can lower $P R$ slightly with decreasing seismic velocity.

In the upper crust, low $V_{p}$, low $V_{s}$ and low $V_{p} / V_{s}$ (low $P R$ ) regions are imaged beneath the Hijima fault, as evidenced by Anomaly (1) in Fig. 7, while the region beneath the Kuresaka-Toge fault shows moderately high $V_{p} / V_{s}$ (moderately high $P R$ ) as shown by Anomaly (2). Our interpretation is that the low velocities and low $V_{p} / V_{s}$ values of the shallow crust beneath the Hijima fault may be at- tributed to the existence of water-filled pores of relatively large aspect ratio, while the low velocities and moderate high $V_{p} / V_{s}$ values beneath the Kuresaka-Toge fault may be due to the existence of water-filled pores of a relatively small aspect ratio (e.g., Takei, 2002; Matsubara et al., 2004; Kato et al., 2006; Nakajima et al., 2006).

In the lower crust, there is a prominent region beneath the Hijima fault at $\sim 17-\mathrm{km}$ depth with low $V_{p}$, low $V_{s}$, high $V_{p} / V_{s}$ of $\sim 1.75-1.8$, and a high $P R$ of $\sim 0.26-0.28$ region, as marked by Anomaly (3) in Figs. 7 and 8. Such anomaly features have been commonly imaged in the lower crust in northeastern Japan from previous travel-time tomographic studies (e.g., Nakajima et al., 2001, 2006; Nakajima and Hasegawa, 2003; Kato et al., 2006; Matsubara et al., 2008) 
(a)
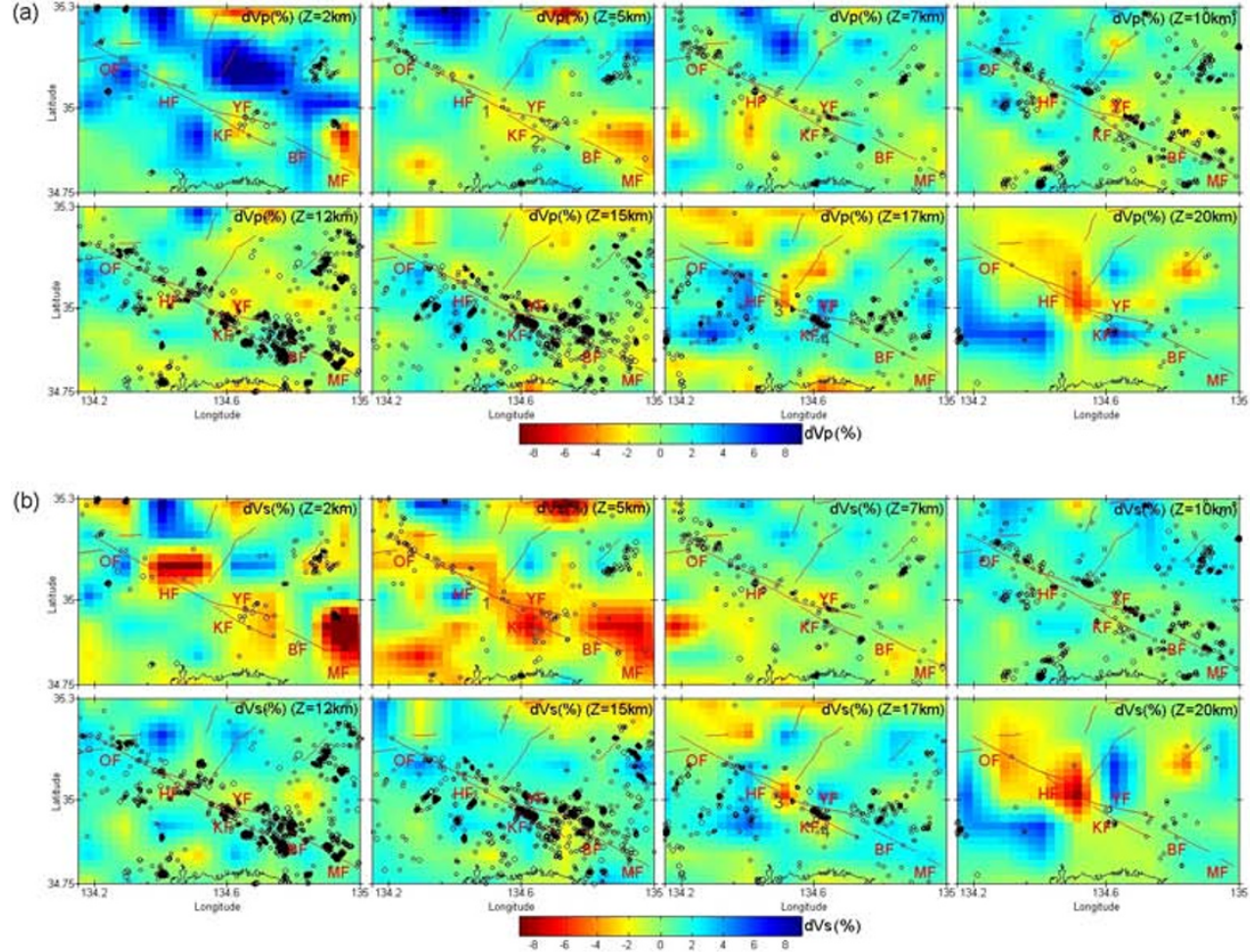

(c)

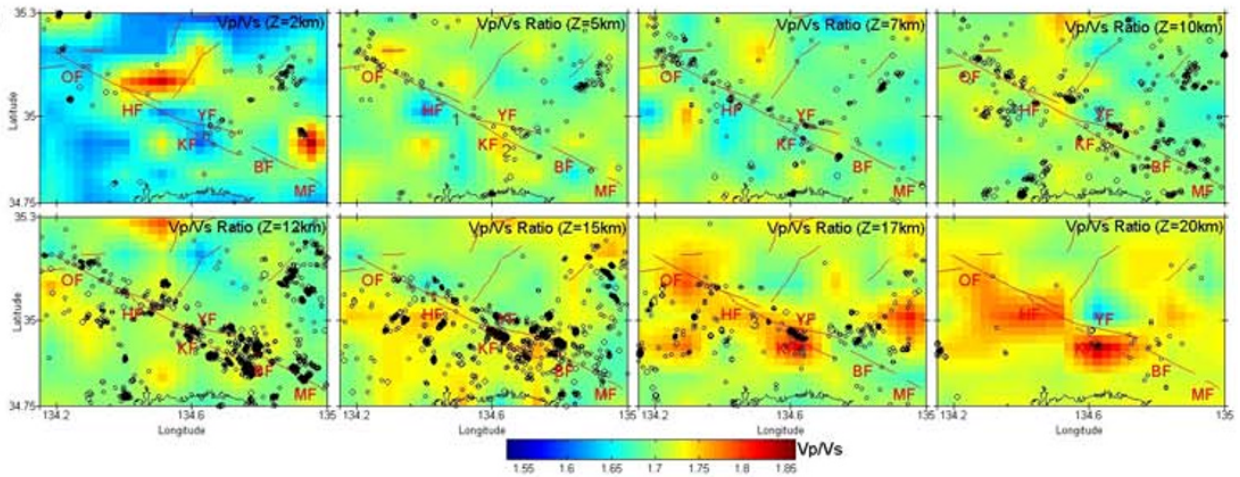

(d)

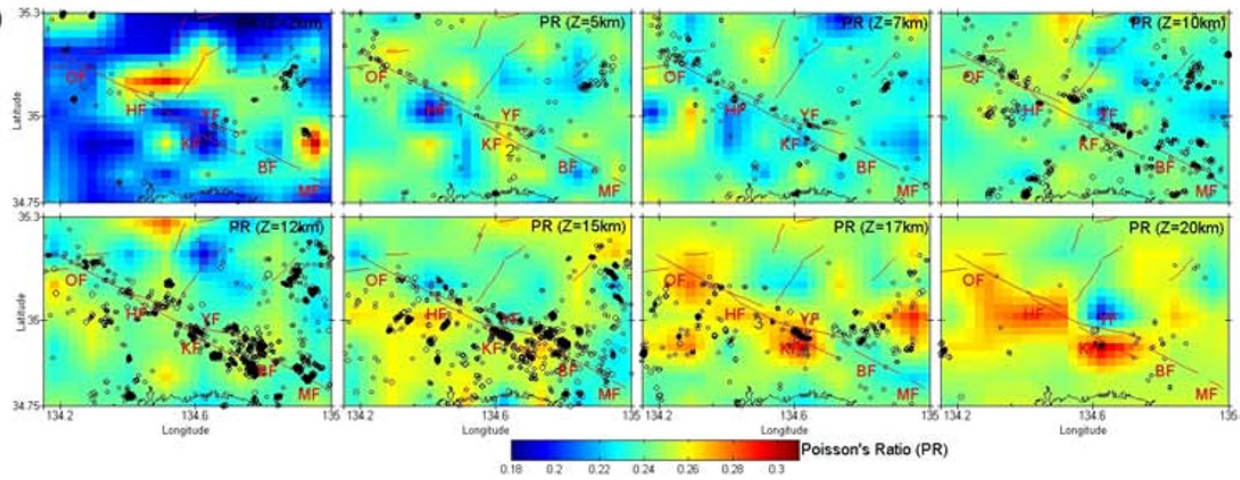

Fig. 7. Map views of (a) $V_{p}$ perturbation, (b) $V_{s}$ perturbation, (c) $V_{p} / V_{s}$ ratio, and (d) Poisson's ratio at depths of 2, 5, 7, 10, 12, 15, 17, and 20 km around the Yamasaki fault zone. For $V_{p}$ and $V_{s}$ perturbation structures, blue and red colors indicate high and low values, respectively. For $V_{p} / V_{s}$ and Poisson's ratio structures, blue and red colors indicate low and high values, respectively. Black circles are relocated hypocenters and red lines are fault traces.

and they are interpreted to be possibly related to partially molten materials. Although Quaternary, or active, volcanoes are not found around the Yamasaki fault zone, Yoshida (2001) showed that temperatures in the lower crust generally exceed the wet solidus of basalt and andesite. The existence of an aseismic Philippine Sea slab beneath Chugoku has been found by analyzing $S c S p$ phases (Nakanishi, 1980) and by the receiver function studies of Ueno et al. (2008) and Shiomi et al. (2008). Partially-melted materials in the lower crust may be associated with upwelling processes in the mantle wedge above the slab. A regional seismic study (Nakajima and Hasegawa, 2007) also imaged a low-velocity 

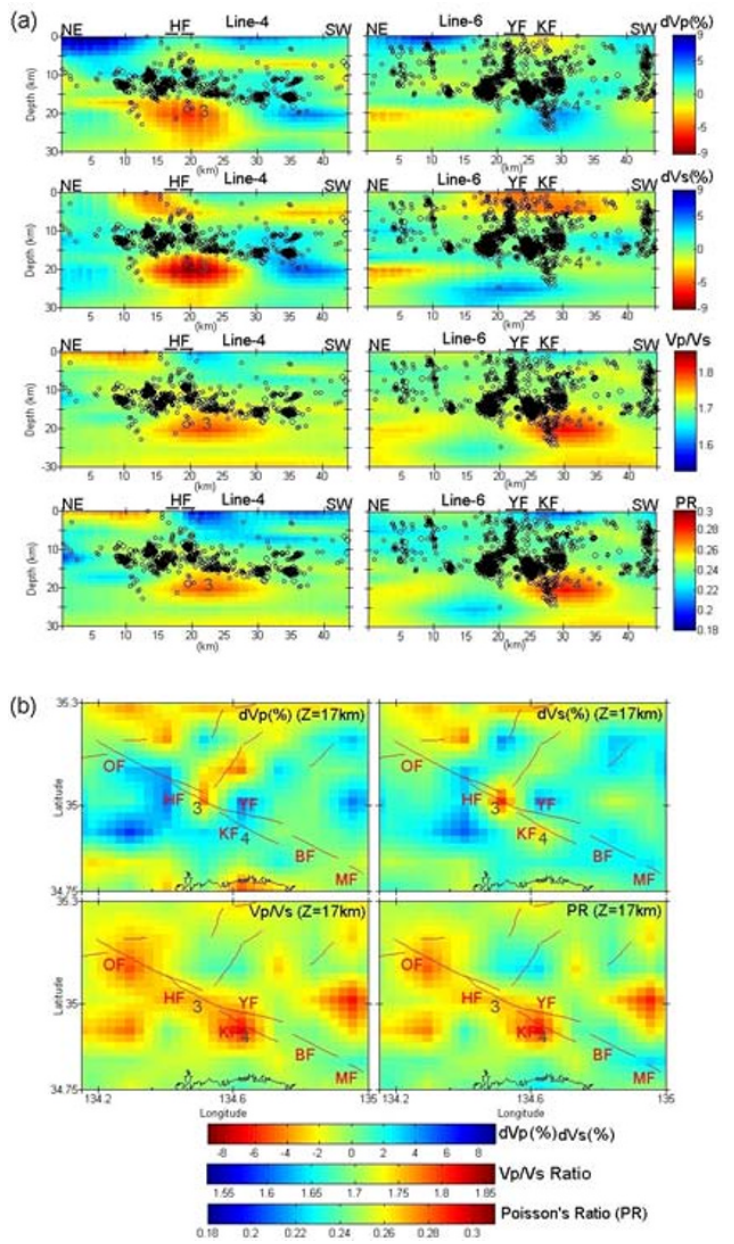

Fig. 8. $V_{p}$ and $V_{s}$ perturbations, $V_{p} / V_{s}$ ratio, and Poisson's ratio structures around the Yamasaki fault zone. (a) Line-4 cross-section through the Hijima fault and Line- 6 cross-section through the Kuresaka-Toge fault. (b) Map views of $V_{p}$ and $V_{s}$ perturbations, $V_{p} / V_{s}$ ratio, and Poisson's ratio structures at a $17-\mathrm{km}$ depth around the Yamasaki fault system. Anomaly (3) shows low velocities, high $V_{p} / V_{s}$, and high Poisson's ratio beneath the Hijima fault, while Anomaly (4) shows a moderately high $V_{p}$, low $V_{s}$, and high $V_{p} / V_{s}$ beneath the Kuresaka-Toge fault. The cross-sections have a vertical exaggeration of 1.8 .

anomaly beneath the Chugoku region. Therefore, partialmelt minerals in the lower crust might be causing Anomaly (3) in this study.

Anomaly (4) in the lower crust at a $17-\mathrm{km}$ depth beneath the Kuresaka-Toge fault in the southeastern part of the Yamasaki fault zone exhibits contrasting properties for $P$ and $S$ waves (moderately high $V_{p}$ and low $V_{s}$ ) with a high $V_{p} / V_{s}$ of 1.76-1.8 and a high $P R$ of about $0.26-0.28$. Such features are difficult to explain by the presence of water and/or melt-filled pores. One plausible explanation is the existence of anhydrous plutonic rocks in this region (Yoshida, 2001), however, this interpretation needs further investigation. The presence of partial melt or fluids beneath the seismogenic zone in the lower crust structure can change the deformation of the fault zone and affect its stress accumulation (Zhao et al., 1996; Hasegawa et al., 2000, 2005; Nakajima et al., 2006).

Low $V_{p} / V_{s}$ values are imaged in the areas where active small earthquakes frequently occur in the Yamasaki fault zone. The low to moderately-high $V_{p} / V_{s}$ zone for seismic- ity clusters are also observed in southern California, and Lin and Shearer (2009) suggested the presence of water-filled cracks with porosities of several percent.

\section{Conclusions}

Using a high-resolution travel-time tomographic inversion, we have successfully determined the threedimensional $V_{p}, V_{s}, V_{p} / V_{s}$ ratio and $P R$ structures to identify crustal heterogeneity around the Yamasaki active fault system. The structure in this region has previously not been studied in such detail. These new results of low velocities and low $V_{p} / V_{s}$ regions in the upper crust at depths down to 5-km below the Yamasaki fault zone, are interpreted as regions of water-filled pores with relatively large aspect ratio. Also, low velocities and high $V_{p} / V_{s}$ regions observed in the lower crust at depths of 15-20 km beneath the Yamasaki fault zone may be associated with the existence of partiallymelted minerals. The existence of these low-velocity regions may affect the long-term strength of the fault zone and change the stress concentration in the seismogenic zone.

Acknowledgments. We thank the Tottori and Abuyama Observatories of the Disaster Prevention Research Institute, Kyoto University, the University of Tokyo, National Research Institute for Earth Science and Disaster Prevention (NIED), National Institute of Advanced Industrial Science And Technology (AIST), Ministry of Education, Culture, Sports, Science, and Technology, Japan (MEXT), and the Japan Meteorological Agency for providing earthquake arrival-time data. We thank the anonymous reviewers for their constructive comments which significantly improved the paper.

\section{References}

Eberhart-Phillips, D., Local earthquake tomography: Earthquake source regions, in Seismic Tomography: Theory and Practice, edited by H. M. Iyer and K. Hirahara, 613-643, CRC Press, Boca Raton, Fla, 1993.

Evans, J., D. Eberhart-Phillips, and C. H. Thurber, User's manual for SIMULPS12 for imaging $V p$ and $V p / V s$ : A derivative of the 'Thurber' tomographic inversion SIMUL3 for local earthquakes, USGS Open-File Report, 94-431, 1994.

Hasegawa, A., A. Yamamoto, N. Umino, S. Miura, S. Horiuchi, D. Zhao, and $\mathrm{H}$. Sato, Seismic activity and deformation process of the overriding plate in the northeastern Japan subduction zone, Tectonophysics, 319, 225-239, 2000.

Hasegawa, A., J. Nakajima, N. Umino, and S. Miura, Deep structure of the northeastern Japan arc and its implications for crustal deformation and shallow seimic activity, Tectonophysics, 403, 59-75, 2005.

Kato, A., E. Kurashimo, N. Hirata, T. Iwasaki, and T. Iidaka, Imaging crustal structure around the western segment of the Atotsugawa fault system, central Japan, Geophys. Res. Lett., 33, L09307, doi:10.1029/2006GL025841, 2006.

Kissling, E., W. L. Ellsworth, D. Eberhart-Phillips, and U. Kradolfer, Initial reference models in local earthquake tomography, J. Geophys. Res., 99, 19635-19646, 1994.

Lin, G. and P. M. Shearer, Evidence for water-filled cracks in earthquake source regions, Geophys. Res. Lett., 36, L17315, doi:10.1029/2009GL039098, 2009.

Matsubara, M., N. Hirata, H. Sato, and S. Sakai, Lower crustal fluid distribution in the northeastern Japan arc revealed by high-resolution 3D seismic tomography, Tectonophysics, 388, 33-45, 2004.

Matsubara, M., K. Obara, and K. Kasahara, Three-dimensional P- and $\mathrm{S}$-wave velocity structure beneath the Japan Islands obtained by high density seismic stations by seismic tomography, Tectonophysics, $\mathbf{4 5 4}$, 86-103, 2008.

Menke, W., Geophysical Data Analysis: Discrete Inverse Theory, Univ. of Calif. San Diego, 1989.

Nakajima, J. and A. Hasegawa, Tomographic imaging of seismic velocity structure in and around the Onikobe volcanic area, northeastern Japan: Implications for fluid distribution, J. Volcanol. Geotherm. Res., 127, 1- 
$18,2003$.

Nakajima, J. and A. Hasegawa, Tomographic evidence for the mantle upwelling beneath southwestern Japan and its implication for arc magmatism, Earth Planet. Sci. Lett., 254, 90-105, 2007.

Nakajima, J., T. Matsuzawa, and A. Hasegawa, Three-dimensional structure of $V p, V s$, and $V p / V s$ beneath northeastern Japan: Implications for arc magmatism and fluids, J. Geophys. Res., 106, 21,843-21,857, 2001.

Nakajima, J., A. Hasegawa, S. Horiuchi, K. Yoshimoto, T. Yoshida, and N. Umino, Crustal heterogeneity around the Nagamachi-Rifu fault, northeastern Japan, as inferred from travel-time tomography, Earth Planets Space, 58, 843-853, 2006.

Nakanishi, I., Precursors to ScS phases and dipping interface in the upper mantle beneath southwestern Japan, Tectonophysics, 69, 1-35, 1980.

Nakao, S., T. Shibutani, and H. Katao, Seismicity around the Yamasaki fault, Annu. Disas. Prev. Res. Ints., Kyoto Univ., 47B, 2004 (in Japanese with English abstract).

Okada, T., N. Umino, T. Matsuzawa, J. Nakajima, N. Uchida, T. Nakayama, S. Hirahara, T. Sato, S. Hori, T. Kono, Y. Abe, K. Ariyoshi, S. Gamage, J. Shimizu, J. Suganomata, S. Kita, S. Yui, M. Arao, S. Hondo, T. Mizukami, H. Tsushima, T. Yaginuma, A. Hasegawa, Y. Asano, H. Zhang, and C. Thurber, Aftershock distribution and 3D seismic velocity structure in and around the focal area of the 2004 mid Niigata prefecture earthquake obtained by applying double-difference tomography to dense temporary seismic network data, Earth Planets Space, 57, 435-440, 2005.

Shibutani, T., H. Katao, and Group for the dense aftershock observations of the 2000 Western Tottori Earthquake, High resolution 3-D velocity structure in the source region of the 2000 Western Tottori Earthquake in southwestern Honshu, Japan using very dense aftershock observations, Earth Planets Space, 57, 825-838, 2005.

Shibutani, T., S. Nakao, K. Nishimura, J. Mori, and Y. Kano, Seismic activity in the area of the Yamasaki fault zone-Summary of data in 30 years-, Abstract, Japan Geoscience Union Meeting 2008, S143-P010, 2008.

Shiomi, K., M. Matsubara, Y. Ito, and K. Obara, Simple relationship between seismic activity along Philippine Sea slab and geometry of oceanic Moho beneath southwest Japan, Geophys. J. Int., 173, 10181029, doi:10.1111/j.1365-246X.2008.03786.x, 2008.

Takei, Y., Effect of pore geometry on $V p / V s$ : From equilibrium geometry to crack, J. Geophys. Res., 107(B2), 2043, 2002.

Toomey, D. R. and G. R. Foulger, Tomographic inversion of local earthquake data from the Hengill-Grensdalur central volcano complex, Iceland, J. Geophys. Res., 94, 17497-17510, 1989.

Ueno, T., T. Shibutani, and K. Ito, Configuration of the continental Moho and Philippine Sea slab in Southwest Japan derived from receiver function analysis: Relation to subcrustal earthquakes, Bull. Seismol. Soc. Am., 98, 2416-2427, doi:10.1785/0120080016, 2008.

Um, J. and C. H. Thurber, A fast algorithm for two-point seismic ray tracing, Bull. Seismol. Soc. Am., 77, 972-986, 1987.

Watanabe, K., K. Nishigami, S. Nakao, and K. Matsumura, Crustal activity of the Yamasaki fault zone before andafter the 1995 Hyogo-ken Nanbu earthquake, Annu. Disas. Prev. Res. Ints., Kyoto Univ., 39B-1, 1996 (in Japanese with English abstract).

Yoshida, T., The evolution of arc magmatism in the NE Honshu arc, Japan, Sci. Rep. Tohoku Univ., 36, 131-149, 2001.

Zhao, D., H. Kanamori, H. Negishi, and D. Wiens, Tomography of the source area of the 1995 Kobe earthquake: Evidence for fluids at the hypocenters?, Science, 274, 1891-1894, 1996.

A. D. Nugraha (e-mail: nugraha@gf.itb.ac.id), S. Ohmi, J. Mori, and T. Shibutani 